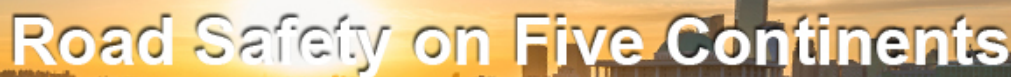

Jeju island, South Korea

May $16-18,2018$

\section{SUICIDE AND ACCIDENT CLASSIFICATION METHODOLOGY}

Anna-Lena Andersson, PhD, Special Adviser Traffic Safety

Swedish Transport Administration / Institute of Clinical Sciences at Sahlgrenska Academy, University of Gothenburg, Department of Orthopedics

Swedish Transport Administration, 40533 Gothenburg, Sweden

Phone: + 467056093 22,

E-mail: anna-lena.andersson@trafikverket.se

Co-author; Kenneth Svensson, Special Adviser Traffic Safety, Swedish Transport Administration. 


\section{INTRODUCTION}

Fatalities in road traffic are not only due to accidents, some of them are suicides. Sweden has since 2010 described statistics on suicides in road traffic separately from fatalities caused by accidents. To implement this, a method has been developed for classification of road traffic fatalities in order to determine if the fatality was caused by an accident or by a suicide.

The work has been carried out in cooperation between The Swedish Transport Administration, The Swedish Transport Agency, The National Board of Forensic Medicine and Suicide Prevention Western Sweden.

\section{OBJECTIVE}

The objective has been to develop and evaluate a method for suicide and accident classification of road traffic fatalities.

\section{METHOD AND MATERIAL}

\subsection{In-depth studies of fatal accidents}

In Sweden all fatalities in road traffic undergo an in-depth study by accident investigators at The Swedish Transport Administration. During 2010-2016 a total of 2111 persons were killed in Swedish road traffic, natural deaths excluded.

\subsection{Classification scale}

A five level classification scale has been developed. Fatalities in level 1 and 2 are classified as suicides in the official statistics.

Table 1: Classification scale for road traffic fatalities

\begin{tabular}{|c|l|}
\hline Level & The result of the examination... \\
\hline 1 & $\begin{array}{l}\text { shows that the manner of death was suicide } \\
- \text { requires a farewell letter or equivalent }\end{array}$ \\
\hline 2 & $\begin{array}{l}\text { strongly supports that the manner of death was suicide } \\
- \text { an almost certain suicide but the intention is based primarily on the course of event and } \\
\text { psychosocial information about the road user }\end{array}$ \\
\hline 3 & $\begin{array}{l}\text { cannot determine whether the manner of death was suicide or the result of an } \\
\text { accident } \\
- \text { the information has not been sufficient in order to determine whether the fatality was the } \\
\text { result of a suicide or an accident }\end{array}$ \\
\hline 4 & $\begin{array}{l}\text { strongly supports that the manner of death was a result of an accident } \\
- \text { an almost certain accident }\end{array}$ \\
\hline 5 & \begin{tabular}{l} 
shows that the manner of death was an accident \\
\hline
\end{tabular} \\
\hline
\end{tabular}

\subsection{Criteria for selection of cases}

Criteria for the selection of cases has been produced based on the traffic event, psychosocial backgrounds factors and knowledge of farewell message, table 2. 
Table 2: Criteria for cases that are to undergo the classification process

1. Farewell message, oral or written, where suicidal intention is clearly communicated and where the traffic event supports a suicidal act

2. A traffic event that supports a suicidal act in combination with knowledge of

a) previous known suicide attempts in the near past

b) indirect suicidal communication in the near past

c) communication about committing suicide or having no reason to live

d) ongoing prolonged depression

e) previous severe emotional stressful life event

3. A traffic event that strongly supports a suicidal act

\subsection{Method for psychosocial examination}

A method for psychosocial examination has been developed. An investigator conducted an expanded psychosocial data collection through contact with the police, relatives, health care institutions and others to get more data for the assessments. The psychosocial examination has been a part of the methodology since 2012 .

\subsection{Expert group for classification}

The selected cases were classified by an expert group of five experienced professionals with knowledge in forensic medicine, psychology and traffic safety. Difficult cases were discussed in a reference group.

\section{RESULTS}

From 2010 to 2016 a total of 182 fatalities have been classified as suicides, 70 as level one and 112 as level two. From 2012 to 2016, when the psychosocial information was included in the analysis, 10 per cent of all fatalities were classified as suicides. In 2010 and 2011 when the extra psychosocial information was not available, 6 per cent of the fatalities were classified as suicides.

Table 3: Result of the suicide and accident classification of road fatalities in Sweden 2010 to 2016. Fatalities in level 1 and 2 were classified as suicides.

\begin{tabular}{|l|c|c|c|c|c|c|c|}
\hline Level & $\mathbf{2 0 1 0}$ & $\mathbf{2 0 1 1}$ & $\mathbf{2 0 1 2}$ & $\mathbf{2 0 1 3}$ & $\mathbf{2 0 1 4}$ & $\mathbf{2 0 1 5}$ & $\mathbf{2 0 1 6}$ \\
\hline 1. suicide & 9 & 7 & 14 & 9 & 7 & 9 & 15 \\
\hline 2. strongly supports... suicide & 7 & 16 & 22 & 19 & 18 & 14 & 16 \\
\hline 3. cannot determine & 10 & 11 & 8 & 13 & 6 & 7 & 10 \\
\hline $\begin{array}{l}\text { 4. strongly supports... } \\
\text { accident }\end{array}$ & 13 & 9 & 5 & 7 & 10 & 12 & 17 \\
\hline 5. accident & 243 & 299 & 272 & 240 & 254 & 240 & 243 \\
\hline Sum & $\mathbf{2 8 2}$ & $\mathbf{3 4 2}$ & $\mathbf{3 2 1}$ & $\mathbf{2 8 8}$ & $\mathbf{2 9 5}$ & $\mathbf{2 8 2}$ & $\mathbf{3 0 1}$ \\
\hline $\begin{array}{l}\text { Percentage of suicides (level } \\
\mathbf{1}+\mathbf{2} \text { ) }\end{array}$ & $\mathbf{5 . 7} \%$ & $\mathbf{6 . 7} \%$ & $\mathbf{1 1 . 2} \%$ & $\mathbf{9 . 7} \%$ & $\mathbf{8 . 5} \%$ & $\mathbf{8 . 5} \%$ & $\mathbf{1 0 . 3}$ \\
\hline
\end{tabular}

Results of the analysis of the suicides in road traffic show that a majority of the persons had been diagnosed with mental illness, but the use of psychopharmacologic drugs seemed to be underused. Psychosocial factors as abuse of alcohol and drugs, unemployment, poor economy were seen as triggering risks, as well as separation problems, revealed crimes and in some cases among elderly, severe somatic diseases. 
More results are presented in the abstract Analysis of suicides in road traffic in Sweden 2010-2015.

\section{DISSCUSSION}

To determine if a fatality is caused by a suicidal act or an accident is a complex task and demands a well-structured and methodical approach. The basis for the assessment is to inquire and examine all available data regarding the accident, including the psychosocial status of the deceased, and then make the classification. A benefit of doubt principle should be applied, i.e. if there is a small possibility that a fatality is due to an accident, it should be classified as a level 3 case and be considered as an accident in the official statistics. For example if persons have a high level of alcohol in the blood, this makes it difficult to know the degree of intent in an act and most of these cases are classified as level 3.

If other countries are to implement the method there is a need for good cooperation between authorities. A factor that can make the assessment difficult is if important documents are missing. If for example an autopsy have not been carried out, important basis for the assessment is absent. However, even if data are lacking countries can still benefit from implementing the methodology. When information is lacking some cases will be classified as level 3 (cannot determine) and this can be a trigger to improve the data collection.

\section{CONCLUSION}

The study can conclude that the suicide and accident classification methodology can be used to determine the number of suicides in road traffic. Psychosocial background factors is needed to be able to reduce the number of uncertain cases. Suicides account for a significant proportion (10 per cent) of road traffic fatalities. This must be considered in the traffic safety work even though suicides are reported separately in the official statistics of road deaths.

\section{FUTURE}

The suicide and accident classification methodology can also be used for other modes of suicides, for example intoxication, drowning, fires, fall from heights etc.

The method was used for the first time to classify Swedish railway fatalities in 2016. A common method of suicide classification of fatalities for all transport modes will contribute to a more reliable basis for suicide prevention measures.

\section{REFERENCES}

Swedish Transport Administration (2014). Vilka dödsfall i vägtrafiken är suicid? Metodbeskrivning samt analys av åren 2010-2013. Publication 2014:113.

Fatalities in road traffic, a result of accidents or suicides? In manuscript. 